\title{
FALÉSIA DA BARONESA, ALCÂNTARA-MARANHÃO: FORMAÇÃO E EVOLUÇÃO RECENTE
}

\author{
Carlos Henrique Santos da Silva ${ }^{(\mathrm{a})}$, Iracilde Maria de Moura Fé Lima ${ }^{(\mathrm{b})}$ \\ (a) Mestre em Geografia, Universidade Federal do Piauí, carlos-henriquess@ @otmail.com \\ (b) Doutora em Geografia, Universidade Federal do Piauí, iracildefelima@ufpi.edu.br
}

Eixo: DINÂMICA E GESTÃO DE ZONAS COSTEIRAS

\begin{abstract}
Resumo
Este trabalho objetiva contribuir para o estudo da dinâmica da linha da costa do Estado do Maranhão, a partir da caracterização da falésia da Baronesa, situada no município de Alcântara. Essa falésia de perfil complexo, representado por camadas sedimentares horizontais variadas e terraço de abrasão marinho, encontra-se altamente suscetível aos processos erosivos, culminando com frequentes desmoronamentos. O desenvolvimento da pesquisa envolveu revisão da literatura; trabalhos de campo; registro fotográfico e utilização de fichas de registro dos elementos e processos atuantes na área. Os resultados encontrados indicaram que, mesmo sendo afetada pela ação antrópica com a retirada de matérias que compõem a face e o terraço de abrasão, a evolução da falésia está diretamente associada aos processos naturais comandados pelo conjunto de agentes costeiros e climáticos e que sua morfodinâmica aponta para o predomínio de processos subaéreos.
\end{abstract}

Palavras-chave: Falésia da Baronesa. Dinâmica da linha de costa. Alcântara-Maranhão.

\section{Introdução}

Os ecossistemas costeiros resultam da interação de ambientes marinhos e terrestres caracterizados por recortes espaciais, diversidade biológica e fragilidade ambiental, sofrendo influência tanto de processos naturais quanto antrópicos (STROHAECKER, 2008).

No Estado do Maranhão, a costa apresenta uma extensão de aproximadamente $640 \mathrm{~km}$, estendendo-se no sentido Oeste-Leste da foz do rio Gurupi, na divisa com o estado do Pará, até o delta do Rio Parnaíba, no limite com o Estado do Piauí. Corresponde ao segundo mais extenso litoral do Brasil e também da região Nordeste.

Em função de suas características geoambientais diferenciadas, a costa maranhense é compartimentada em Litoral Ocidental, Golfão Maranhense e Litoral Oriental (FEITOSA; TROVÃO, 2006), estando a área de estudo localizada no Golfão Maranhense. Este se apresenta com cerca de $10 \mathrm{~km}$ de abertura para o Oceano Atlântico, separando dois tipos de costas: a faixa Noroeste, com "falsas rias" bastante ativas; e o segundo a Leste, que corresponde a um trecho retilíneo, sendo ambos fortemente controlados pela estrutura geológica, conforme El-Robrini et al (2006).

Esse golfão se caracteriza como um complexo estuarino, formado a oeste pela baía de São Marcos onde desagua o sistema fluvial Mearim/Grajaú/Pindaré, e onde se localiza a falésia da Baronesa, no município de Alcântara, objeto deste estudo. A sua porção ocidental é formada pela baía de São José, 
XVII Simpósio Brasileiro

de Geografia Fisica Aplicada

I Congresso Nacional

de Geografia Física
OS DESAFIOS DA GEOGRAFIA FÍSICA NA FRONTEIRA DO CONHECIMENTO

Instituto de Geociências - Unicamp

Campinas - SP

28 de Junho à 02 de Julho de 2017

para onde converge outro grande sistema fluvial formado pelos rios Itapecuru e Munim, encontrandose entre esta e a baía de São Marcos a Ilha do Maranhão, na qual se localiza a cidade de São Luís, capital do estado do Maranhão (UEMA, 2002).

No Estado do Maranhão, as falésias ocorrem principalmente nos setores Ocidental e Golfão, moldadas a partir do Pleistoceno, mas principalmente no Holoceno, quando o mar se posicionou próximo ao nível atual (SOUZA FILHO, 1995; EL-ROBRINI et al, 2006).

No Brasil o termo falésia é usado indistintamente para designar as formas do relevo litorâneo abruptas ou escarpadas ou, ainda, os desnivelamentos de igual aspecto no interior do continente (GUERRA; GUERRA, 2001). Assim, refere-se a uma superfície fortemente inclinada, onde a terra se encontra com o mar, sendo que as falésias costeiras apresentam uma característica geomorfológica de primeira ordem de significância, uma vez que ocorrem ao longo de cerca de $80 \%$ das linhas costeiras do mundo (EMERY; KUHN, 1982).

Outra definição, considera a falésia como um ressalto não coberto pela vegetação, com declividade muito acentuada e de alturas variáveis, localizadas na linha de contato entre a terra e o mar. Para esse autor, à medida que se ampliam nessa superfície os processos erosivos comandados pelas ondas, a falésia vai recuando para o continente formando, assim, o terraço de abrasão. Os sedimentos erodidos são, então, transportados e depositados na plataforma continental, alimentando praias ou formando terraço de construção marinha, como uma feição plana suavemente inclinada em conjunto com o terraço de abrasão (CHRISTOFOLETTI, 1986).

Como destaca Rossetti (2008), os ambientes costeiros constituem laboratórios naturais que fornecem informações relativas à dinâmica de oscilação do nível do mar em tempos passados, cujos registros ficam preservados nas sucessões sedimentares da paisagem costeira atual. Assim, sua evolução no tempo geológico permite reconstruir os padrões de variação do nível do mar, bem como entender os fatores intrínsecos e extrínsecos que influenciaram suas mudanças através do tempo.

A escolha da falésia da Baronesa como objeto deste estudo se deve à crescente ocupação desse setor do litoral maranhense, principalmente voltado para o turismo, associado ao fato que essa área tem chamado a atenção a partir da realização de pesquisas que vêm identificando aí importantes vestígios do período Cretáceo. Dentre esses, encontram-se fosseis vegetais e animais, além dos que se associam a eventos tectônicos e sedimentológicos, o que possibilita ampliar o entendimento de parte do passado geológico do Maranhão e de sua evolução (CARVALHO, 2001; SANTOS et al, 2012).

\section{Procedimentos Técnico-Operacionais}

Para a realização desta pesquisa utilizou-se a abordagem sistêmica, em função da complexidade dos processos que envolve a formação e dinâmica das falésias marinhas, principalmente por envolver 
OS DESAFIOS DA GEOGRAFIA FÍSICA NA FRONTEIRA DO CONHECIMENTO

Instituto de Geociências - Unicamp

Campinas - SP

28 de Junho à 02 de Julho de 2017

vários materiais e processos na perspectiva de suas inter-relações de dependências mútuas e de seus aspectos funcionais (ROSS, 2006).

O trabalho iniciou-se com o levantamento de publicações científicas e outros documentos com dados referentes à especificidade do tema em questão. A partir de então foram realizados trabalhos de campo, para reconhecimento e análise visual das feições e características morfológicas e geológicas, como aspectos sedimentológicos, cores, textura, estrutura, além da identificação de possíveis interferências antrópicas na dinâmica costeira natural, através do uso e ocupação da falésia e de seus registros através de fotografias.

Durante o trabalho de campo fez-se a aplicação de uma ficha, necessária a organização de dados sobre a feição, incluindo dados gerados durante a pesquisa, para posterior sistematização e análise de informações pertinentes à caracterização física; identificação dos processos operantes e uso e ocupação da falésia da Baronesa e análise da morfodinâmica local.

\section{Resultados e Discussões}

\subsection{Caracterização da área de estudo}

No município de Alcântara há inúmeras falésias que têm como base geológica o membro Alcântara. Apresentam níveis carbonáticos, areníticos, argilosos e margosos, formando um cordão no sentido Norte-Sul, sendo a maioria interceptada por rios que desaguam na baía de São Marcos e por paleofalésias.

A falésia da Baronesa apresenta cerca de 348 metros de extensão e 29 metros de altura média, tendo as

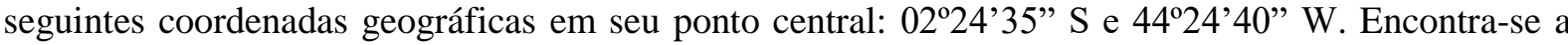
noroeste da baía de São Marcos, recuada para o interior do continente, formando uma pequena enseada (Figura 1). A sua evolução está associada à erosão marinha e principalmente à erosão subaérea, ocasionando desmoronamentos e surgimentos de ravinas em sua face, processos estes que influenciam o ritmo de sua regressão e, consequentemente, a retrogradação da linha da costa local.

Atualmente esta costa vem sendo afetada com a interferência antrópica, por se localizar próxima à sede municipal de Alcântara e por possuir materiais abundantes muito utilizados para revestimentos de ruas desta cidade, como a dolomita que reveste o terraço de abrasão formado na base da falésia da Baronesa.

O município de Alcântara e, consequentemente, suas falésias estão inseridas na bacia marginal de São Luís. Esta é uma bacia do tipo rift, originada a partir dos esforços tectônicos que resultaram na formação do Atlântico Equatorial. Sua sedimentação data das Eras Mesozoica e Cenozoica, sendo que a maior parte da sedimentação é datada do Mesozoico, constituindo as rochas da Formação Itapecuru, do Período Cretáceo, correspondendo a terceira e última unidade sedimentar da Província Parnaíba, recoberta por formações superficiais da Era Cenozoica (BIZZI et al, 2003). 

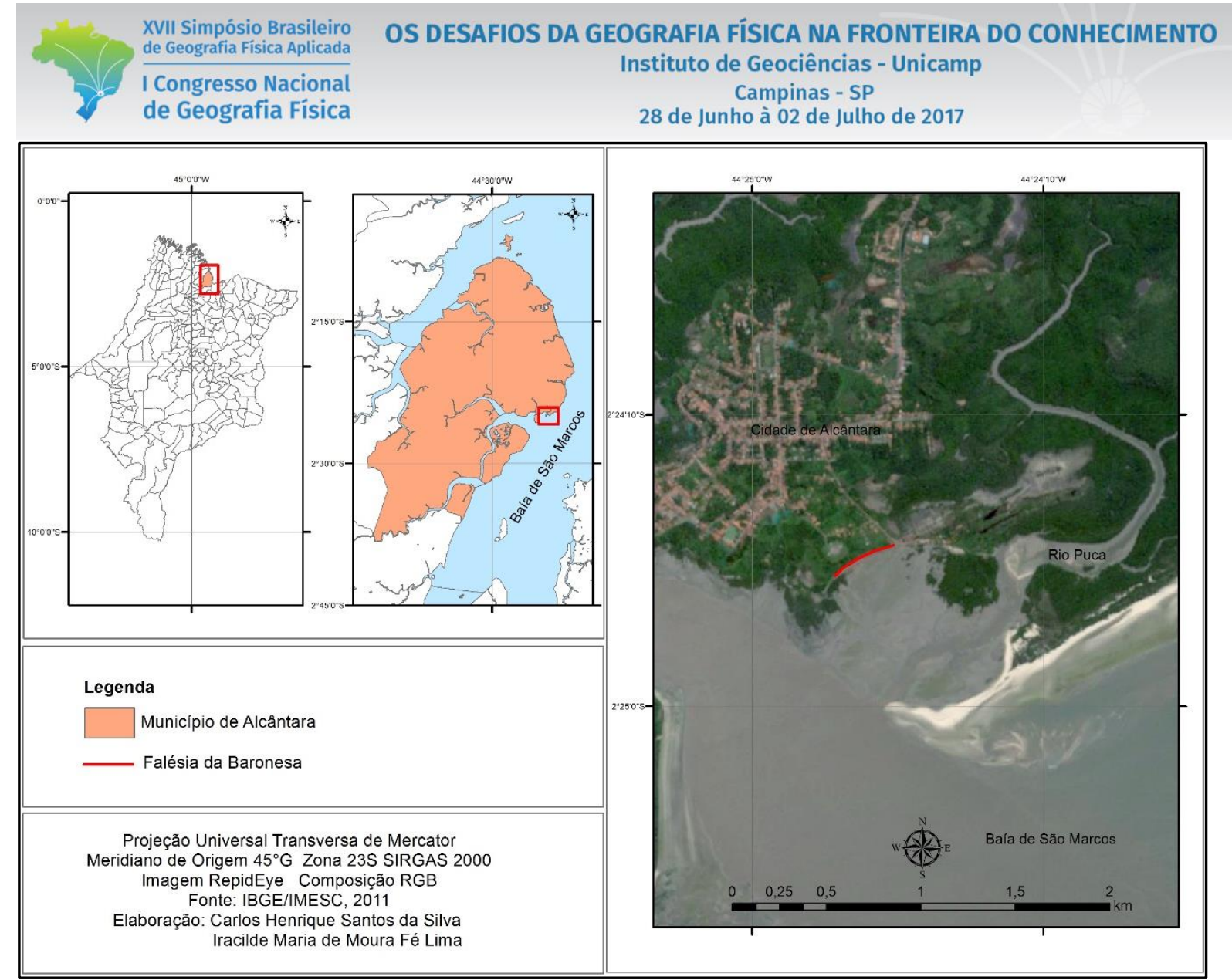

Figura 1 - Mapa de localização da Falésia da Baronesa. Fonte: Org. SILVA E LIMA (2017). Base de dados: Imagem RepidEye (2011).

Para Rodrigues et al (1994), litoestratigraficamente a bacia de São Luís encontra-se caracterizada por três unidades principais: Formação Itapecuru (Mesozoico - Cretáceo Superior), Formação Barreiras (Cenozoico - Terciário - Plioceno) e Formação Açuí (Cenozoico - Quaternário Pleistoceno/Holoceno).

A área de estudo encontra-se na porção dessa bacia formada pelo membro Alcântara da Formação Itapecuru. Este membro se compõe de siltitos e folhelhos vermelhos, coesos, de estratificação planoparalela, disposta de forma tabular em camadas decimétricas, que intercalam alguns bancos lenticulares de calcário creme esbranquiçados. As rochas que ocorrem no município de Alcântara e na área da falésia da Baronesa, são descritas por Rodrigues et al. (1994) na seguinte posição: da base para o topo apresentam litofácies de arenitos de grã fina a média, submaturos mal selecionados, quartzosos, vermelhos com estratificação cruzada acanalada de grande porte; arenitos finos a médios, maciços; arenitos avermelhados e esbranquiçados, grã fina a média, com estratificação plano-paralela, arenitos brancos a vermelhos com estratificação cruzada festonada. As litofácies sílticas sobrepostas à essa primeira camada são siltitos vermelhos de laminação plano-paralela; pelitos com estruturas wavy, linsen e climbing, calcilutitos com estratificação ondulada. A interpretação de sua gênese está relacionada a planície costeira, com ambientes de alta energia com praias, influências deltaicas e canais fluviais passando a ambiente de baixa a média energia em ambiente de baías ou golfos, com influências de maré. 
As marés da área de estudo se caracterizam por uma hidrodinâmica regida pelo sistema de marés semidiurnas (duas preamares e duas baixa-mares por dia lunar, com intervalos proporcionais de cerca de 6h), com amplitude média de 4,6m. Essas marés podem atingir até 7,2m quando das grandes sizígias, sendo essa amplitude a responsável por profundas modificações no processo de sedimentação e erosão da costa. As ondas geradas pelos ventos são importantes agentes de energia, pois provocam erosão e deposição, através da remobilização de areia para diversas áreas do sistema praial. As correntes litorâneas, dependendo do ângulo de incidência, conseguem transportar grandes quantidades de sedimentos e colocá-los em movimento pela ação das ondas, fazendo com que eles se desloquem por longas distâncias. Esses agentes exercem grande influência na dinâmica costeira e são responsáveis pela modelado e configuração das feições morfológica (SILVA; LIMA, 2016).

Os agentes climáticos também contribuem para a evolução da falésia da Baronesa. Decorrente de sua localização numa região de baixa latitude, na zona costeira e apresentar altitudes modestas, apresenta uma dinâmica climática, resultante de diversos fatores, influenciados principalmente pelas massas de ar, os ventos alísios, a Zona de Convergência Intertropical (ZCIT), temperaturas e regime pluviométrico. Utilizando a classificação de Köppen, o clima desta área enquadra-se na categoria Aww', ou seja, úmido tropical sem estação fria (A), com estação seca acentuada (w), e chuvas concentradas principalmente no outono (w') (IMESC, 2011).

Por estar próximo do equador, o município de Alcântara e suas falésias apresentam altas temperaturas que são amenizadas, principalmente, por sua proximidade com a Amazônia e ao Oceano Atlântico. A média anual de temperatura é superior a $27^{\circ} \mathrm{C}$ sendo que a partir do mês de julho a temperatura média sofre uma elevação gradativa até encontrar seu ápice no mês de novembro. Nos meses seguintes a temperatura volta a cair e o período entre fevereiro e julho são os mais frios (SILVA; LIMA, 2016). O período de maior precipitação está situado entre janeiro e julho, com totais pluviométricos entre 2000 e $2400 \mathrm{~mm}$ anuais. Entre os meses de julho e dezembro, o nível de precipitação fica mais baixo e estável (UEMA, 2002).

Os ventos predominantes na área são os alísios de NE-E. Estes são importantes por contribuírem com os índices de transporte e deposição de sedimentos e por influenciarem a intensidade das ondas e geração das correntes litorâneas, que afetam a costa.

A partir desses dados, infere-se que dois processos morfodinâmicos influenciam a modelagem do relevo. No primeiro semestre, predomina o intemperismo químico, provocando processos pluvioerosivos, onde as falésias desmoronam com maior facilidade pelo encharcamento de água em seu interior e provocando sulcos, ravinamentos e por vezes em voçorocas de sua face. No período mais seco predomina a desagregação mecânica, quando o vento transporta sedimentos da falésia, para outras áreas. 
Atualmente esta costa vem sendo afetada também com a interferência antrópica, por se localizar próxima a sede municipal e por possuir materiais abundantes muito utilizados para revestimentos de ruas da cidade de Alcântara, como a dolomita que reveste o terraço de abrasão formado na base da falésia da Baronesa.

\subsection{Gênese e evolução da falésia da Baronesa}

A falésia da Baronesa é formada por rochas do membro Alcântara, e modeladas durante o Pleistoceno e o Holoceno, principalmente nos últimos 6.000 anos, quando o mar ficou próximo do seu nível atual. Em sua base encontram-se arenitos finos de coloração esverdeada, com grãos bem arredondados, esfericidade alta e bem selecionados, apresentando estratificação cruzada complexa de pequeno e grande porte, com estruturas internas como laminações cruzadas cavalgantes, recobertas por filmes de argila. Estas são compostos principalmente por quartzo, mas apresentam outros minerais como: clorita, mica, palygorskita e feldspatos. Acima do arenito, ocorre uma grande alternância de níveis de pelitos, com coloração esverdeada e avermelhada, esta última coloração é atribuída a hematita, com porções ricas em silte e areia muito fina. Os pelitos apresentam argilominerais predominantes em sua composição como: palygorskita, illita e traços de caulinita, sendo intercalados com níveis dolomíticos, finos de coloração branca a acinzentada, que variam de 70 a $80 \mathrm{~cm}$, que são caracterizados principalmente pela presença de dolomita e por vezes pequenas quantidades de palygorskita (AMORIM, 2010).

$\mathrm{O}$ arenito compõe principalmente a base da falésia, enquanto os dolomitos ocorrem em delgadas faixas horizontais, de cor creme a acinzentada, intercalando os arenitos. A primeira faixa, mais próxima da base da falésia, apresenta uma largura de cerca de $22 \mathrm{~cm}$ de material mais resistente, enquanto as demais apresentam-se menos resistente por apresentarem maior nível de intemperismo e, por vezes, perfazendo uma linha descontínua, intercalando uma série de pelitos esverdeados e avermelhados.

Próximo ao topo da falésia, encontra-se visível uma camada de stone line, indicando que esta se formou durante períodos mais secos, a partir de depósitos superficiais, contendo materiais angulosos e homogêneos, de natureza elúvio-coluvial sendo, portanto, posterior à gênese da formação Itapecuru (Figura 2).

Com relação à sua dinâmica atual, o clima local influencia os tipos e a intensidade dos processos que aí ocorrem. Assim, destaca-se que as médias das precipitações pluviométricas anuais são condicionantes para o predomínio de processos subaéreos e escoamento superficial na face da falésia. Estes ocorrem, principalmente, no período em que se concentram as precipitações pluviométricas favorecendo o desencadeamento de processos erosivos de maior intensidade e o consequente surgimento de sulcos, ravinas e sua evolução para voçorocas na face da falésia. Outra característica dessa dinâmica corresponde aos deslizamentos translacionais ativos, formando depósito de tálus na base da falésia, principalmente no final das incisões das ravinas, cujos materiais são posteriormente 
carreados pelo trabalhado dos agentes oceanográficos, fazendo recuar a linha de costa para o continente.

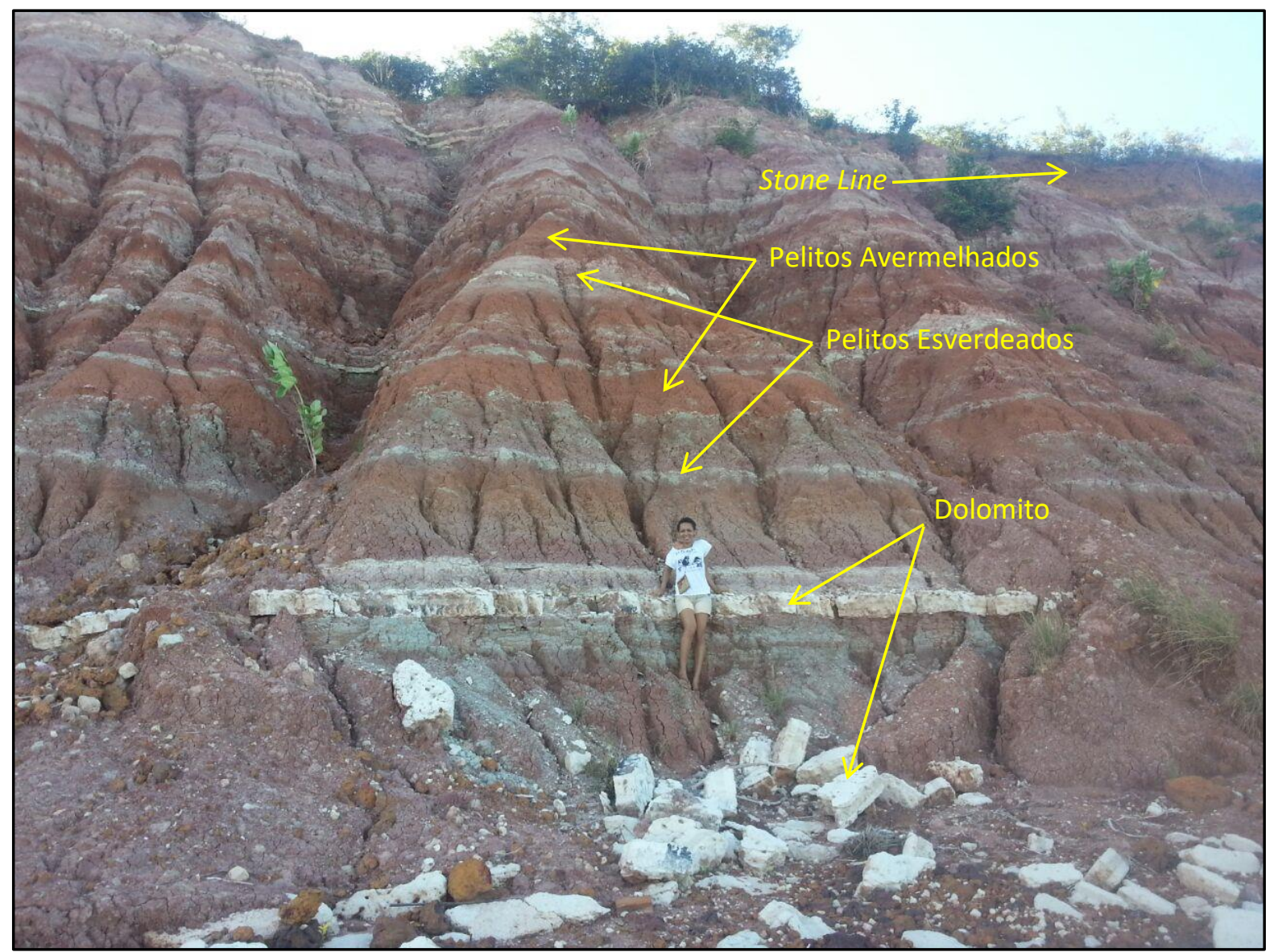

Figura 2 - Falésia da Baronesa, identificando o dolomito, pelitos esverdeados e avermelhados e stone line. Fonte: os autores, 2015.

Como decorrência da direção dos fluxos desses processos, que ocorrem de forma perpendicular aos estratos rochosos, as ravinas e voçorocas fazem incisões nas camadas de dolomitos em sentido vertical, mesmo este tendo fratura em forma laminar, provocando também a queda de blocos desse material, conforme se observa na Figura 3. Quando predomina estiagem, ocorre uma contração dos argilominerais que compõem principalmente os pelitos, dando um aspecto de rachaduras na face da falésia (Figura 3B). 


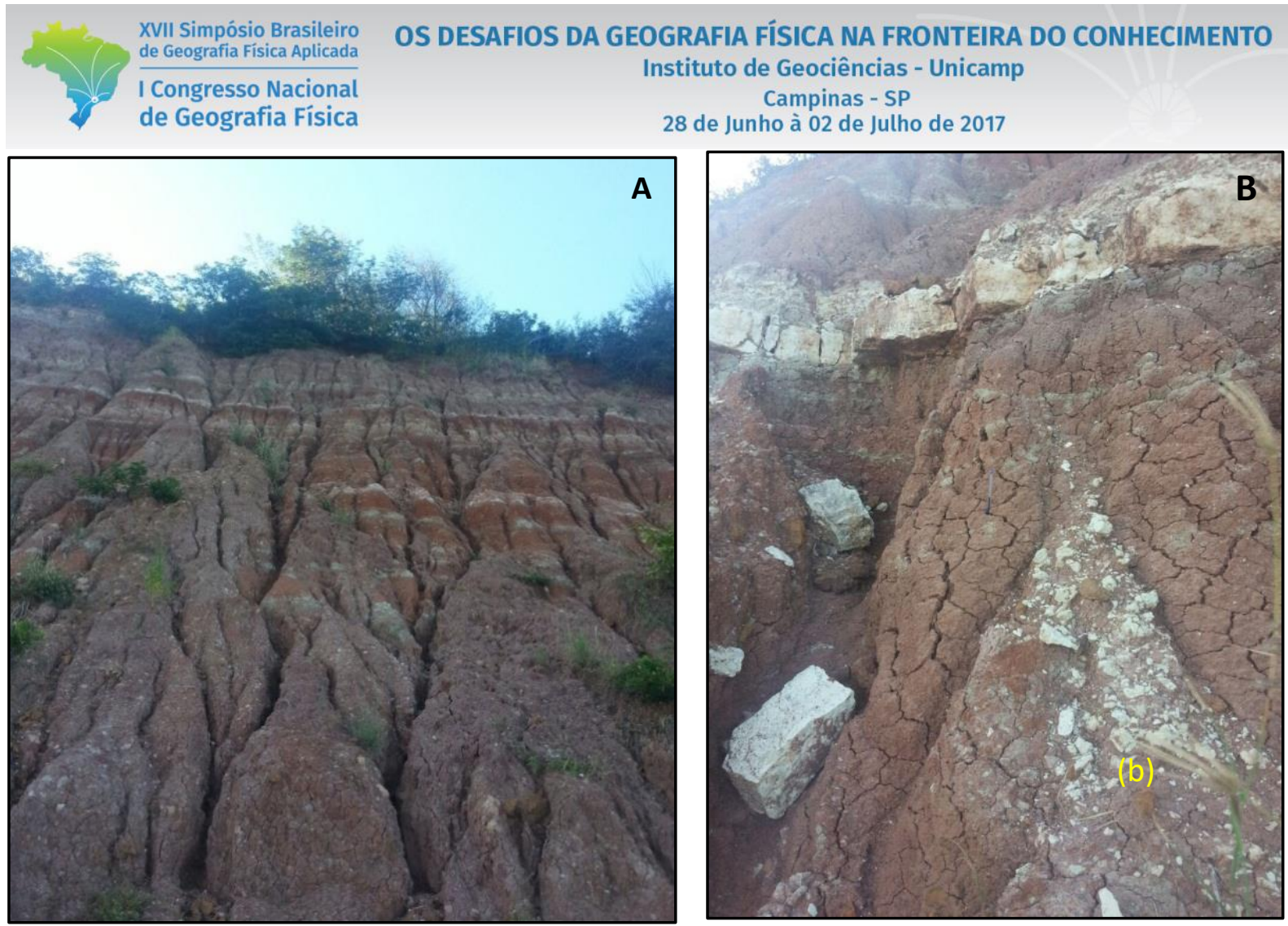

Figura 3 - (A) Sulcos e ravinas na face da falésia. (B) Detalhe de rachaduras na face da falésia. Fonte: os autores, 2015.

Quanto a dinâmica marinha, constatou-se que esta afeta a falésia principalmente nas grandes marés de sizígias, ou seja, marés acima de $5 \mathrm{~m}$, enquanto as ondas pequenas e de baixa energia são persistentes, provocando o solapamentos na falésia formando caneluras. Estas vão se aprofundando, até o colapso da face da falésia por efeito da gravidade. Ocorrem deslizamentos e queda de blocos, formando um depósito tálus na base da falésia, que são posteriormente remodelados e deslocados pelas ondas, marés e correntes. Decorrente da insolação e dos sais componentes do mar, alguns materiais que compõem o tálus sofrem processos químicos de oxi-redução, tornando-os endurecidos, que vão compor o terraço de abração. Este é composto principalmente por dolomitos e petroplintitas que despencam da face ou afloram na base da falésia.

Assim, este terraço é formado por sedimentos provenientes da erosão e do movimento de massa se caracterizando como material solto, originários da face e do topo da falésia, além de materiais que sofreram processos químicos e se tornaram endurecidos. Estes correspondem principalmente a petroplintitas, materiais expostos na face da falésia que, dependendo da erosão, despencam, acumulando-se na base da falésia e, posteriormente, são modelados e distribuídos ao longo da base da falésia pelos agentes oceanográficos.

Quedas e afloramento de dolomitos são comuns alimentando o terraço de abração. Posteriormente estes blocos vão sendo fragmentados pelos agentes oceanográficos tornando-se mais arredondados e tendo seu tamanho reduzido e, frequentemente, apresentando pequenas cavidades em sua face (Figura 4A). Além destes, observou-se também outro material na composição desse terraço de abração, 
XVII Simpósio Brasileiro

de Geografia Fisica Aplicada

I Congresso Nacional

de Geografia Física

\section{OS DESAFIOS DA GEOGRAFIA FÍSICA NA FRONTEIRA DO CONHECIMENTO \\ Instituto de Geociências - Unicamp \\ Campinas - SP \\ 28 de Junho à 02 de Julho de 2017}

embora ocorram em menor expressão quantitativa, são blocos arredondas de composição mineralógica mista, proveniente da litificação de pelitos avermelhados (Figura 4B).

Quanto ao uso e ocupação da área, constatou-se que a ocupação humana próximo a falésia da Baronesa ainda é insipiente, mas como a área apresenta grande beleza cênica, este setor vem sendo objeto de especulação imobiliária. A ausência de residências, casas de veraneio e pousadas, bares e outros empreendimentos dispostos na base ou sopé e no topo da falésia, associada a significativas porções de áreas com cobertura vegetal arbórea, apontam para sua relativa proteção dos agentes erosivos mais intensos, retardando os processos comandados por agentes climáticos, embora estes se reflitam no espesso manto de intemperismo devido a inclinação da face da falésia.

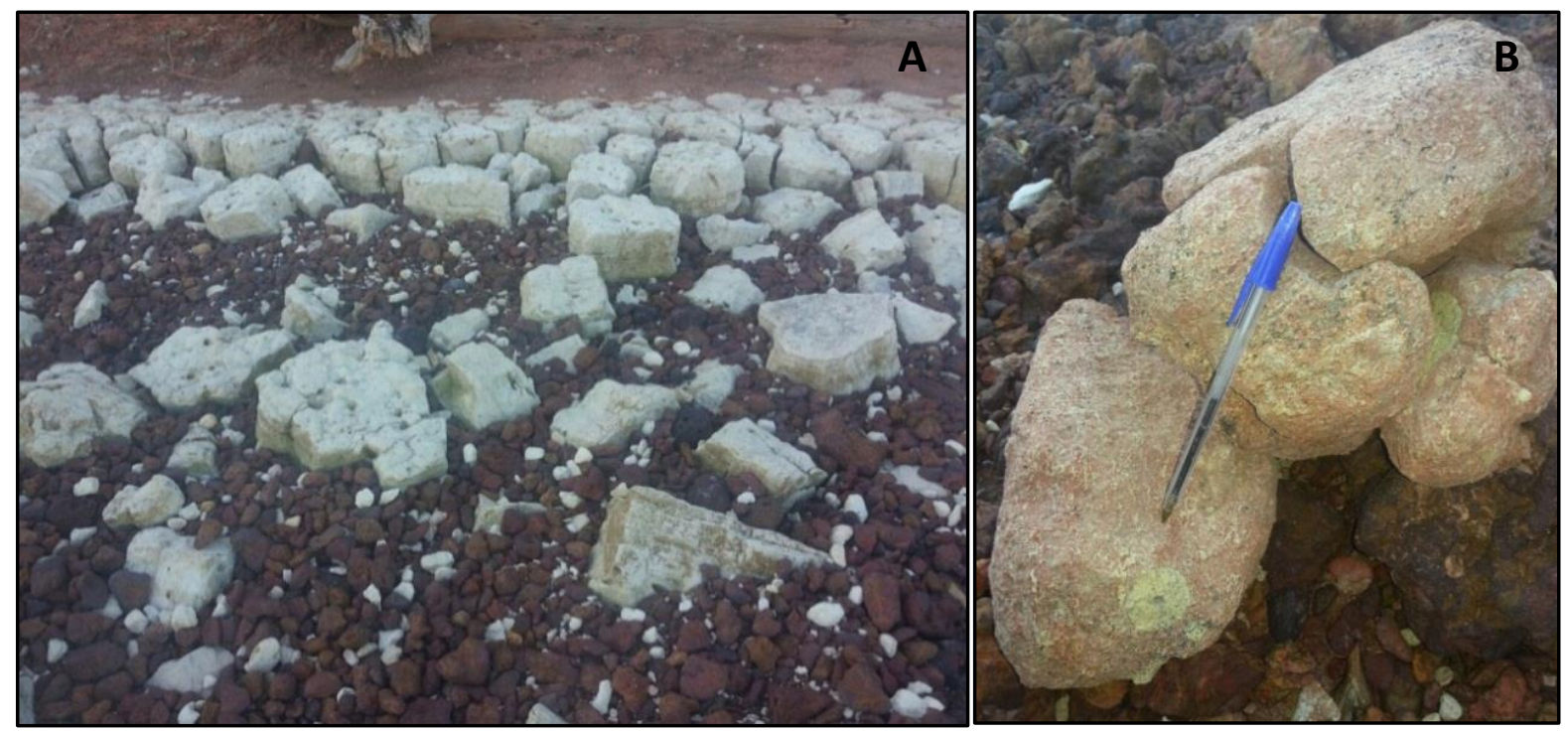

Figura 4 -Terraço de abrasão, onde se observa em (A) constituição predominante de blocos de dolomitos e arenitos ferruginosos e em (B) detalhes do material de composição mista que ocorre em pequena proporção nesse terraço. Fonte: os autores, 2015.

Identificou-se, no entanto, que tem havido nas últimas décadas uma interferência direta da população local especificamente sobre a falésia da Baronesa, através da retirada dos seus materiais componentes, notadamente de blocos de dolomito que revestem o terraço de abrasão e protegem a base da falésia. Esse material vem sendo utilizado pelos moradores da cidade de Alcântara, como ornamentação de residências, revestimento de pisos, batentes de portas e janelas, como também o poder público municipal, que tem utilizado esses blocos de rocha para a pavimentação de grande parte das ruas desta cidade.

Pelas observações realizadas in situ, por ocasião de diversos trabalhos de campo na área, assevera-se que a falésia da Baronesa encontra-se numa fase de tendência a uma certa estabilização, em relação ao trabalho dos agentes oceanográficos que contribuem para sua evolução, e uma tendência ao aumento do ataque dos agentes subaéreos, que também atuam na sua dinâmica. Os movimentos de massa recorrentes e o eventual transporte e deposição de sedimentos, estão contribuindo para a formação de 
XVII Simpósio Brasileiro

de Geografia Física Aplicada

I Congresso Nacional

de Geografia Física

\section{OS DESAFIOS DA GEOGRAFIA FÍSICA NA FRONTEIRA DO CONHECIMENTO \\ Instituto de Geociências - Unicamp \\ Campinas - SP \\ 28 de Junho à 02 de Julho de 2017}

um depósito de talús permanente na base da falésia que, por sua vez, está sendo ocupada por vegetação, já que os agentes marinhos não conseguem mais deslocá-lo.

Outros efeitos desses processos podem ser observados principalmente pela formação de uma lagoa costeira à frente da falésia da Baronesa, o spit arenoso, responsável pela gênese dessa lagoa costeira, que se prolonga de duas formas diferenciadas. Na primeira este se desloca no sentido nordestesudoeste e na segunda no sentido sudeste-noroeste, formando um semicírculo. A formação desse spit e o seu prolongamento ganharam maior proporção a partir da década de 1970, associados a migração de sedimentos arenosos deslocados pelas correntes litorâneas durante a preamar, como também pela deposição eólica, após a baixa-mar em que as canaletas ou ridges encontram-se alimentadas permanentemente por grandes quantidades de areias (EL-ROBRINI et al, 2006) (Figura 5A e B).

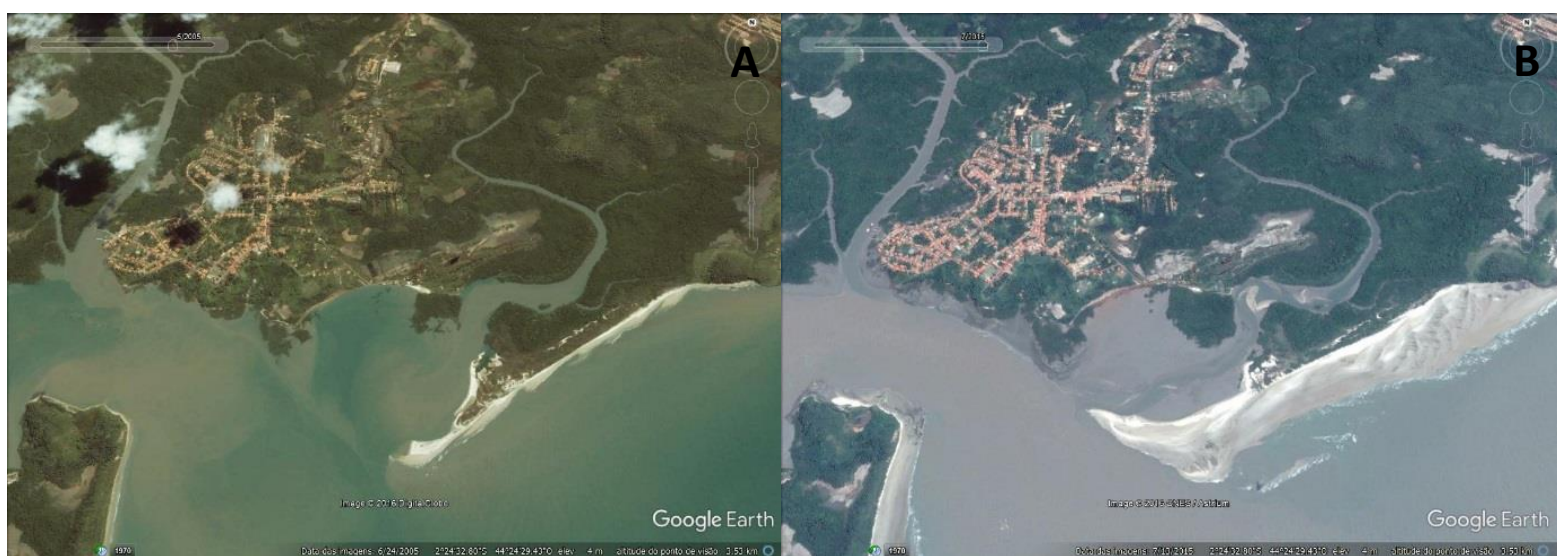

Figura 5 - Evolução do spit arenoso na área de estudo: em (A) formação de spit arenoso em 2005; e em (B) spit arenoso em 2015. Fonte: Google Earth (2005 e 2015).

O assoreamento do rio Puca, em função da perda da dinâmica e velocidade de sua corrente, associado à deposição de sedimentos ao longo do seu leito formando bancos de areia, favorece o prolongamento do spit arenoso, pois o rio não tem energia para transportar esses sedimentos que compõem este spit para o interior da baía de São Marcos, fazendo com que este mude sua foz constantemente. Como consequência, os agentes marinhos como ondas, marés e correntes litorâneas não exercem mais influência significativa na área uma vez que, inicialmente com o barramento realizado pelo spit, as ondas chegam com metade da sua altura, e assim as marés só conseguem solapar a base da falésia em grandes marés de sizígias, maiores que 5 metros, além de provocarem uma modificação no direcionamento das correntes.

Dessa forma, a praia arenosa antes existente ao longo da falésia da Baronesa desapareceu quase por completo, dando lugar a sedimentos lamosos. $\mathrm{O}$ aparecimento de manguezais em praticamente toda a extensão da falésia aponta para a estabilização desta e a formação de uma lagoa, uma vez que o mangue só se estabelece onde há suprimentos de águas salgadas e doces. 
Outro fator que corresponde a um forte indicativo de que a falésia da Baronesa tenha passado de um estado de dinâmica mais acentuada para outro de menor intensidade, tendo em vista que a inclinação acentuada de sua face entre $60^{\circ}$ e $45^{\circ}$ e apresente o depósito de tálus colonizado por vegetação em algumas áreas na base da falésia o que favorece à sua estabilização.

\section{Conclusões}

A falésia da Baronesa é uma feição geomorfológica que apresenta características singulares, refletindo a evolução do ambiente em que está inserido, como a dinamicidade dos períodos climáticos e das alternâncias do nível do mar no decorrer dos períodos geológicas mais recentes, registadas na alternância de camadas sedimentares expostas na sua face voltada para o mar. Esta falésia encontra-se, assim, numa faixa da costa maranhense que pode ser encarada como laboratório natural, incitando experiências e descobertas, como os que se encontrou a partir deste estudo.

A falésia é dominada por processos subaéreos, principalmente no primeiro semestre do ano, gerados pelas intensas precipitações pluviométricas, provocando escoamento superficial na face, carreamento de partículas do solo, deslizamentos e incisões, como sulcos e ravinas, que evoluem para voçorocas e deposição de sedimentos formando o tálus na sua base.

A erosão costeira é pouco atuante no local, principalmente porque as ondas, correntes e marés só atingem a base da falésia em marés de sizígias ou quando de grandes tempestades, que fazem o mar ficar mais revolto. A presença de elementos como o perfil inclinado da falésia, a preponderância do depósito de tálus com vegetação na base, a predominância de processos subaéreos mais severos e a eventual formação de uma lagoa costeira individualizada por um spit arenoso, são provas de que a falésia aos poucos deixa de sofrer com a ação das ondas, marés e correntes, mudando seu estágio evolutivo de intensa atividade para uma atividade moderada.

Observou-se também que a presença na faixa de praia de arenitos ferruginosos e dolomitos que formam o terraço de abrasão atuam como uma importante proteção natural à evolução da falésia, contribuindo para a dissipação da energia das ondas marinhas incidentes. Porém, a exploração pela população de blocos de dolomito desse terraço em passado recente, constituiu um fator que contribuiu para que a falésia recuasse mais rapidamente, ao provocar a desestabilização de sua face. Assim, a redução desse uso, bem como a ausência de ocupação humana no seu topo, certamente estão contribuindo para retardar, pelo menos em parte, o ritmo evolução da falésia Baronesa.

Os resultados encontrados indicaram que, mesmo sendo a falésia afetada pela ação antrópica com a retirada de matérias que compõem a face e o terraço de abrasão, a sua evolução está diretamente associada aos processos naturais comandados pelo conjunto de agentes costeiros e climáticos. Assim, considerando que os processos marinhos não mais atuam diretamente sobre ela, sua morfodinâmica aponta para que se considere que esse trecho da costa maranhense tenha sua evolução atual comandada predominantemente pelos processos subaéreos. 


\section{REFERÊNCIAS}

AMORIM, K. B. Mineralogia e geoquímica dos pelitos e carbonatos da Formação Alcântara, cretáceo superior da bacia de São Luís-Grajaú. Monografia de conclusão de curso. Universidade Federal do Pará, Belém - PA: 2010.

BIZZI, L. A. SCHOBBENHAUS, C., VIDOTTI, R. M. \& GONÇALVES, J. H. (Editores.) Geologia, Tectônica e Recursos Minerais do Brasil. CPRM-SGB - Brasília, 2003, 674p.

CARVAlHO, I. S. Pegadas de Dinossauros em depósitos estuarinos (Cenomaniano) da Bacia de São Luís (MA), Brasil. In: ROSSETTI, D. F.; GÒES, A. M.; TRUCKENBRODT (Editores). O Cretáceo na Bacia de São Luís-Grajaú. Belém: Museu Paraense Emílio Goeldi, Coleção Friedrich Katzer, 2001.

CHISTOFOLETTI, A. Geomorfologia. São Paulo: Edgar Blücher, 2. ed.,1986.

EL-ROBRINI, M.; MARQUES J, V.; SILVA, M.M.A.; EL-ROBRINI, M.H.S.; FEITOSA, A.C.; TAROUCO, J.E.F.; SANTOS, J.H.S.; VIAN, J. R. Erosão e Progradação do Litoral Brasileiro-Maranhão. In: MUEHE, D. (Org.). Erosão e Progradação do Litoral Brasileiro-Maranhão. Programa de Geologia e Geofísica Marinha (PGGM). Brasília: MMA, 2006.

EMERY, K.O., and KUHN, G.G., 1982, Sea cliffs; their processes, profiles, and classification: Geological Society of America Bulletin, v. 93, p. 644-654.

FEITOSA, A. C e TROVÃO, J. R. Atlas escolar do Maranhão: Espaço geo-histórico e cultural. João PessoaPB: Editora Grafset, 2006.

GUERRA, A. T.; GUERRA, A. J. T. Novo dicionário geológico-geomorfológico. 2 ed. Rio de Janeiro: Bertrand Brasil, 2001.

IMESC. Situação Ambiental da Ilha do Maranhão. Instituto Maranhense de Estudos Socioeconômicos e Cartográficos. São Luís: IMESC, 2011.

RODRIGUES, T. L. N.; ARAÚJO, C.C.; CAMAZZATO, E.; RAMGRAB, G.E. (Orgs.). São Luís, Folha SA23-2-A, Cururupu, Folha SA-23-X-C, escala 1: 1.000.000. Brasília: Companhia de Pesquisa de Recursos Minerais, Programa Levantamentos Geológicos Básicos do Brasil, 1994.185 p.

ROSS, Jurandyr. Ecogeografia do Brasil: subsídios para o planejamento ambiental. São Paulo: Oficina de Textos, 2006.

ROSSETTI, D. F. Ambientes Costeiros In: FLORENZANO, Teresa Gallotti (Org.). Geomorfologia: conceitos e técnicas atuais. São Paulo: oficina de textos, 2008.

SANTOS, A.C.G.; NUNES, Z.M.; FARIAS FILHO, M.S.; ARAÚJO, F.L.; MOREIRA, J.F. Análise Geológica, Geomorfológica e Ambiental Da Ilha do Cajual em Alcântara - Ma. ANAIS IX SINAGEO, Rio de Janeiro, 2012. Disponível em: http://www.sinageo.org.br/2012/trabalhos/4/4-567-400.html. Acesso em: 20 jan. 2017.

SILVA, C. H.S.; LIMA, I. M. M. F. Caracterização do terraço de abrasão da falésia da Baronesa e sua utilização na cidade de Alcântara-MA. REGNE, Vol.2, Nºspecial, 2016.

SOUZA FILHO, P.W.M., 1995. A planície costeira bragantina (NE do Pará): Influência das variações do nível do mar na morfoestratigrafia costeira durante o Holoceno, 1995, 123 f. (Dissertação de Mestrado). Programa de Pós-Graduação. Universidade Federal do Pará. Centro de Geociências. Belém, 1995.

STROHAECKER, T. M. Dinâmica populacional. In: ZAMBONI, A e NICOLADI, J.L. (Orgs.). Macrodiagnóstico da zona costeira e marinha do Brasil. Brasília: MMA, 2008.

UEMA - Gerencia de Planejamento e Desenvolvimento Econômico, Laboratório de Geoprocessamento. Atlas do Maranhão. São Luís: GEPLAN, 2002. 